\title{
MicroRNA expression in multiple myeloma is associated with genetic subtype, isotype and survival
}

\author{
Jianxiang Chi ${ }^{1,2}$, Erica Ballabio ${ }^{1}$, Xiao-He Chen ${ }^{1}$, Rajko Kušec ${ }^{3}$, Steve Taylor ${ }^{4}$, Deborah Hay ${ }^{5}$, Daniela Tramonti ${ }^{1}$, \\ Nigel J Saunders ${ }^{6}$, Timothy Littlewood ${ }^{5}$, Francesco Pezzella ${ }^{1}$, Jacqueline Boultwood ${ }^{1}$, James S Wainscoat ${ }^{1}$, \\ Christian SR Hatton ${ }^{5}$ and Charles H Lawrie ${ }^{1 *}$
}

\begin{abstract}
Background: MicroRNAs are small RNA species that regulate gene expression post-transcriptionally and are aberrantly expressed in many cancers including hematological malignancies. However, the role of microRNAs in the pathogenesis of multiple myeloma (MM) is only poorly understood. We therefore used microarray analysis to elucidate the complete miRNome (miRBase version 13.0) of purified tumor (CD138+) cells from 33 patients with MM, 5 patients with monoclonal gammopathy of undetermined significance (MGUS) and 9 controls.

Results: Unsupervised cluster analysis revealed that MM and MGUS samples have a distinct microRNA expression profile from control CD138 ${ }^{+}$cells. The majority of microRNAs aberrantly expressed in MM (109/129) were up-regulated. A comparison of these microRNAs with those aberrantly expressed in other B-cell and T-cell malignancies revealed a surprising degree of similarity ( 40\%) suggesting the existence of a common lymphoma microRNA signature. We identified 39 microRNAs associated with the pre-malignant condition MGUS. Twenty-three (59\%) of these were also aberrantly expressed in MM suggesting common microRNA expression events in MM progression. MM is characterized by multiple chromosomal abnormalities of varying prognostic significance. We identified specific microRNA signatures associated with the most common IgH translocations $(t(4 ; 14)$ and $t(11 ; 14))$ and del(13q). Expression levels of these microRNAs were distinct between the genetic subtypes (by cluster analysis) and correctly predicted these abnormalities in $>85 \%$ of cases using the support vector machine algorithm. Additionally, we identified microRNAs associated with light chain only myeloma, as well as IgG and IgA-type MM. Finally, we identified 32 microRNAs associated with eventfree survival (EFS) in MM, ten of which were significant by univariate (logrank) survival analysis.
\end{abstract}

Conclusions: In summary, this work has identified aberrantly expressed microRNAs associated with the diagnosis, pathogenesis and prognosis of $\mathrm{MM}$, data which will prove an invaluable resource for understanding the role of microRNAs in this devastating disease.

Reviewers: This article was reviewed by Prof. Neil Smalheiser, Prof. Yuriy Gusev, and an unknown reviewer.

\section{Background}

Multiple myeloma (MM) is a plasma cell (PC) malignancy with an annual incidence of over 14,000 cases in the US alone. MM is essentially an incurable disease with a median survival of $\sim 3$ years that accounts for nearly $2 \%$ of deaths from cancer and about $20 \%$ of

\footnotetext{
* Correspondence: charles.lawrie@ndcls.ox.ac.uk

'Nuffield Department of Clinical Laboratory Sciences, University of Oxford, John Radcliffe Hospital, Oxford, UK

Full list of author information is available at the end of the article
}

deaths from hematological cancers [1]. Newer therapies, however, are resulting in improvements in the median survival [2]. Recent advances in molecular and genetic research have lead to the realization that $\mathrm{MM}$, although defined histologically as a single entity, encompasses a wide range and frequently complex mixture of genomic abnormalities which differ in both their molecular pathogenesis and prognostic significance. The recent discovery of short non-coding RNA molecules that regulate gene expression post-transcriptionally, known as

\section{Biomed Central}


microRNAs, represent yet another level of complexity in our understanding of gene regulation and as such could further our understanding of the pathogenesis of MM.

MicroRNAs have been demonstrated to have diagnostic and prognostic potential in cancer [3-7] and it has been suggested that microRNA expression profiling can distinguish cancers according to both the cellular nature and the developmental stage of the tumor with a greater degree of accuracy than traditional gene expression analysis [8]. There is increasingly strong evidence that microRNAs are involved in the pathogenesis of many cancers including $\mathrm{B}$ and $\mathrm{T}$ cell lymphomas $[9,10]$. There is however little known about the role that microRNAs play in MM.

Therefore we undertook a comprehensive study using microarray technology to elucidate the complete miRNome (miRBase version 13.0) of purified tumor (CD138 ${ }^{+}$) cells from the bone marrow of $33 \mathrm{MM}$ and 5 MGUS patients (and 9 controls). In order to investigate microRNA expression in different genetic subtypes MM cases were classified cytogenetically by FISH. These data were then correlated with genetic subtype and clinical parameters.

\section{Results}

Most aberrantly expressed microRNAs associated with MM are up-regulated

We elucidated the complete (miRBase v.10.1) microRNA profile of $\mathrm{CD} 138^{+}$plasma B-cells from bone marrow of $33 \mathrm{MM}$ patients, 5 MGUS, 9 controls, and 4 well established MM cell lines (NCI-H929, JJN3, Thiel and RPMI8226). Unsupervised cluster analysis revealed that MM samples and MM cell lines have a distinct microRNA profile from counterpart controls (Figure 1A). Furthermore, although MGUS samples did not cluster together, they had a microRNA profile more similar to MM samples (and cell lines) than controls.

To identify microRNAs that are aberrantly expressed in MM patient samples we compared expression levels with controls by ANOVA. This resulted in the identification of 129 microRNAs $(P<0.05)$, only $20(15 \%)$ of which were down-regulated in MM samples (Table 1). Of these 29 and 24 were previously identified as being aberrantly expressed in MM by the studies of Zhou et al [11] and Pichiorri et al [12] respectively. In order to validate the microarray data, eight microRNAs chosen for their previous association with MM or other hematological malignancies were measured by qRT-PCR. These data were consistent with the microarray results (Figure 2). Many microRNAs are encoded in clusters, and members of these clusters often exhibit the same pattern of expression [13]. A lower proportion of MMassociated microRNAs (42/109 (38\%); Table 1) were encoded in clusters than generally observed $(215 / 474$

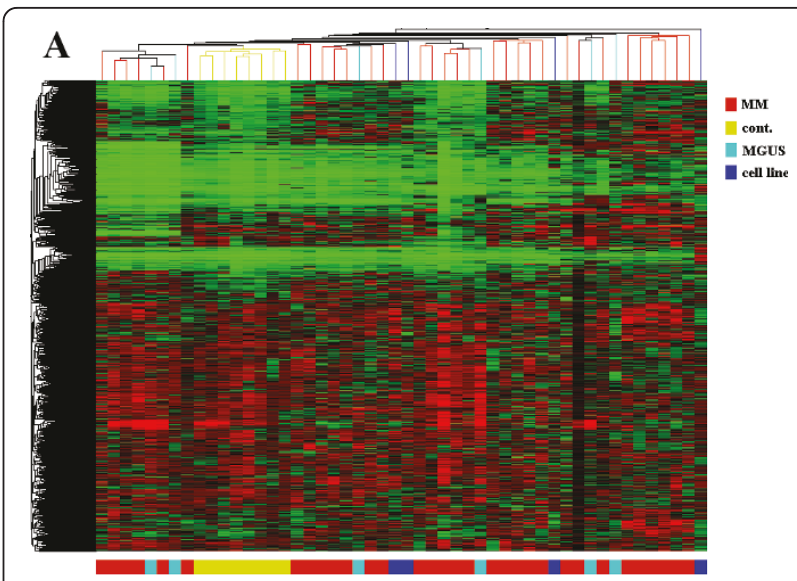

B

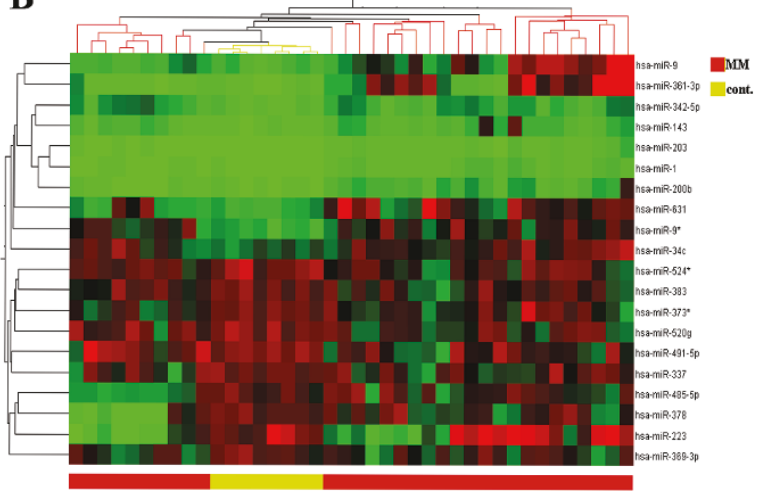

Figure 1 The microRNA expression profile of $M M$ is distinct from counterpart normal plasma cells. (A) Unsupervised cluster analysis of microRNA expression data for MM ( $n=33)$, control ( $n=$ 9) and MGUS ( $n=5$ ) samples. (B) Heat map depicting expression levels of 10 most discriminatory up- and down-regulated microRNAs (Table 1) between MM and control samples.

(45\%)) (source- http://www.diana.pcbi.upenn.edu/cgibin/miRGen/v3/Cluster.cgi).

Expression levels of the $129 \mathrm{MM}$-associated microRNAs were distinct between MM and control samples (Additional file 1 Figure S1). Indeed using only expression levels of the ten most discriminatory (by $P$-value) up- and down-regulated microRNAs distinguished samples by cluster analysis (Figure 1B) and correctly predicted samples as either MM or control for 36/41 (88\%) samples using the leave-one-out cross-validation support vector machine (SVM) algorithm.

The microRNA profile of MGUS patient samples is distinct from MM and controls

MGUS is generally believed to represent a pre-malignant form of MM [14]. To examine microRNA expression in this condition we initially compared the profile of PC cells from MGUS patients with that of controls. Thirty-nine microRNAs were identified as being 
Table 1 MicroRNAs differentially expressed $(P<0.05)$ between MM $(n=33)$ and controls $(n=9)$ depicting chromosomal location and where relevant their expression within a microRNA cluster.

\begin{tabular}{|c|c|c|c|c|c|}
\hline Order & microRNA & adj. $P$ value & Fold change & Chromosome & Cluster \\
\hline 1 & miR-1 & $5.41 \mathrm{E}-06$ & 3.15 & $20 q 13.33 / 18 q 11.2$ & $1-1,133 a$ \\
\hline 2 & miR-203 & 2.09E-05 & 2.64 & $14 q 32.33$ & - \\
\hline 3 & $\operatorname{miR}-342$ & $2.25 \mathrm{E}-05$ & 3.94 & $14 q 32.2$ & - \\
\hline 4 & miR-631 & $2.25 \mathrm{E}-05$ & 4.24 & $15 q 24.2$ & - \\
\hline 5 & miR-200a & 3.17E-05 & 5.50 & $12 \mathrm{p} 13.31$ & $141-200 c$ \\
\hline 6 & miR-34c & $5.95 \mathrm{E}-05$ & 3.31 & $11 q 33.1$ & $34 b-34 c$ \\
\hline 7 & miR-361 & $5.95 \mathrm{E}-05$ & 12.66 & Xq21.2 & - \\
\hline 8 & miR-9* & $7.64 \mathrm{E}-05$ & 4.48 & $1 q 22 / 5 q 14.3 / 15 q 26.1$ & - \\
\hline 9 & miR-200b & $8.52 \mathrm{E}-05$ & 4.97 & $12 \mathrm{p} 13.31$ & $141-200 c$ \\
\hline 10 & miR-9 & $8.52 \mathrm{E}-05$ & 5.07 & $1 q 22 / 5 q 14.3 / 15 q 26.1$ & - \\
\hline 11 & miR-151 & 1.19E-04 & 2.67 & $8 q 24.3$ & - \\
\hline 12 & $m i R-218$ & $1.42 \mathrm{E}-04$ & 3.96 & $4 p 15.31 / 5 q 34$ & - \\
\hline 13 & $\operatorname{miR}-28-3 p$ & $1.90 \mathrm{E}-04$ & 2.52 & $3 q 28$ & - \\
\hline 14 & miR-200c & $2.10 \mathrm{E}-04$ & 5.26 & $12 \mathrm{p} 13.31$ & $141-200 c$ \\
\hline 15 & $\operatorname{miR}-21$ & $2.72 \mathrm{E}-04$ & 2.45 & $17 q 23.1$ & - \\
\hline 16 & $\operatorname{miR}-378$ & $2.72 \mathrm{E}-04$ & 2.96 & $5 q 33.1$ & - \\
\hline 17 & miR-548d-5p & $2.72 \mathrm{E}-04$ & 3.10 & $8 q 24.13 / 17 q 24.2$ & - \\
\hline 18 & miR-621 & $2.72 \mathrm{E}-04$ & 9.64 & $13 q 14.11$ & - \\
\hline 19 & miR-140-5p & 3.91E-04 & 2.78 & $16 \mathrm{q} 22.1$ & - \\
\hline 20 & miR-634 & 4.77E-04 & 2.25 & $17 q 24.2$ & - \\
\hline 21 & miR-616 & $6.16 \mathrm{E}-04$ & 2.69 & $12 q 13.3$ & - \\
\hline 22 & miR-130a & 7.81E-04 & 2.48 & $11 q 12.1$ & - \\
\hline 23 & miR-593 & 7.81E-04 & 3.29 & $7 q 32.1$ & - \\
\hline 24 & miR-708 & $7.81 \mathrm{E}-04$ & 3.32 & $11 q 14.1$ & - \\
\hline 25 & $m i R-200 a^{*}$ & $7.81 \mathrm{E}-04$ & 4.08 & 12p13.31 & $141-200 c$ \\
\hline 26 & miR-340 & $9.03 \mathrm{E}-04$ & 2.41 & $5 q 35.3$ & - \\
\hline 27 & $\operatorname{miR}-760$ & $1.12 \mathrm{E}-03$ & 2.44 & $1 \mathrm{p} 22.1$ & - \\
\hline 28 & miR-885-3p & $1.39 \mathrm{E}-03$ & 2.55 & $3 p 25.3$ & - \\
\hline 29 & miR-590-3p & $1.42 \mathrm{E}-03$ & 3.50 & $7 q 11.23$ & - \\
\hline 30 & miR-885-5p & $1.61 \mathrm{E}-03$ & 3.34 & $3 p 25.3$ & - \\
\hline 31 & $\operatorname{miR}-221$ & $2.36 \mathrm{E}-03$ & 2.85 & Xp11.3 & $221-222$ \\
\hline 32 & miR-7 & $2.36 \mathrm{E}-03$ & 3.66 & $9 q 21.32 / 15 q 26.1 / 19 p 13.3$ & - \\
\hline 33 & $\operatorname{miR}-188-5 p$ & $2.94 \mathrm{E}-03$ & 2.18 & Xp11.23 & $532-660$ \\
\hline 34 & $\operatorname{miR}-338$ & $2.94 \mathrm{E}-03$ & 2.35 & $17 q 25.3$ & $338-657$ \\
\hline 35 & miR-222 & $2.94 \mathrm{E}-03$ & 2.47 & Xp11.3 & $221-222$ \\
\hline 36 & miR-99a & $2.94 \mathrm{E}-03$ & 3.47 & $19 q 13.33$ & $99 b-125 a$ \\
\hline 37 & miR-891a & 3.06E-03 & 2.31 & Xq27.3 & 890-891 \\
\hline 38 & miR-452 & 3.77E-03 & 2.57 & Xq28 & $452-224$ \\
\hline 39 & miR-98 & 4.09E-03 & 3.04 & Xp11.22 & 98-let-7f \\
\hline 40 & $\operatorname{miR}-629$ & 4.09E-03 & 3.14 & $15 q 23$ & - \\
\hline 41 & $m i R-515-3 p$ & 4.11E-03 & 5.90 & Xq27.3 & - \\
\hline 42 & $\operatorname{miR}-192$ & 4.20E-03 & 2.44 & $11 q 13.1$ & 192-194 \\
\hline 43 & miR-454 & 4.36E-03 & 2.82 & $17 q 22$ & - \\
\hline 44 & miR-151-3p & 4.59E-03 & 2.22 & $8 q 24.3$ & - \\
\hline 45 & miR-141 & $5.20 \mathrm{E}-03$ & 3.37 & $12 \mathrm{p} 13.31$ & $141-200 c$ \\
\hline 46 & $\operatorname{miR}-128 b$ & 5.35E-03 & 2.25 & $2 p 21.3 / 3 p 22.3$ & - \\
\hline 47 & $\operatorname{miR}-1227$ & $5.64 \mathrm{E}-03$ & 2.82 & $19 p 13.3$ & - \\
\hline 48 & miR-128a & $6.51 \mathrm{E}-03$ & 2.82 & $2 p 21.3 / 3 p 22.3$ & - \\
\hline 49 & miR-205 & $6.94 \mathrm{E}-03$ & 3.15 & $1 q 32.2$ & - \\
\hline 50 & $\operatorname{miR}-27 b$ & 7.30E-03 & 2.81 & $9 q 22.32$ & $23 b-24$ \\
\hline
\end{tabular}


Table 1 MicroRNAs differentially expressed $(P ?<$ ? 0.05) between MM $(n=33)$ and controls $(n=9)$ depicting chromosomal location and where relevant their expression within a microRNA cluster. (Continued)

\begin{tabular}{|c|c|c|c|c|c|}
\hline 51 & miR-608 & $7.67 \mathrm{E}-03$ & 2.38 & $10 q 24.31$ & - \\
\hline 52 & miR-432 & 7.99E-03 & 2.41 & $14 q 32.2$ & $337-136$ \\
\hline 53 & $\operatorname{miR}-220$ & 8.08E-03 & 2.86 & $X q 25$ & - \\
\hline 54 & $\operatorname{miR}-135 a$ & 8.30E-03 & 2.80 & $3 p 21.1 / 12 q 23$ & - \\
\hline 55 & miR-34a & $8.42 \mathrm{E}-03$ & 2.58 & $1 p 36.22$ & - \\
\hline 56 & $\operatorname{miR}-28$ & $8.72 \mathrm{E}-03$ & 1.94 & $3 q 28$ & - \\
\hline 57 & $\operatorname{miR}-412$ & $9.41 \mathrm{E}-03$ & 2.12 & $14 q 32.2$ & $323-656$ \\
\hline 58 & miR-877 & $9.84 \mathrm{E}-03$ & 1.91 & $6 p 21.33$ & - \\
\hline 59 & miR-628-5p & $1.04 \mathrm{E}-02$ & 2.09 & $15 q 21.3$ & - \\
\hline 60 & miR-532-3p & $1.06 \mathrm{E}-02$ & 1.95 & $19 q 13.41$ & - \\
\hline 61 & $\operatorname{miR}-625$ & 1.15E-02 & 2.11 & $14 q 23.3$ & - \\
\hline 62 & $\operatorname{miR}-34 b$ & 1.19E-02 & 2.07 & $11 \mathrm{q} 33.1$ & $34 b-34 c$ \\
\hline 63 & miR-31 & $1.28 \mathrm{E}-02$ & 2.62 & $9 p 21.3$ & - \\
\hline 64 & miR-181a & $1.46 \mathrm{E}-02$ & 2.05 & $1 q 32.1 / 9 q 33.3$ & 181a-181b \\
\hline 65 & $m i R-32$ & $1.46 \mathrm{E}-02$ & 2.80 & $9 q 31.3$ & - \\
\hline 66 & $\operatorname{miR}-106 b$ & $1.51 \mathrm{E}-02$ & 2.48 & $7 q 22.1$ & $106 b-25$ \\
\hline 67 & miR-146a & $1.52 \mathrm{E}-02$ & 2.14 & $5 q 33.3$ & - \\
\hline 68 & $\operatorname{miR}-210$ & $1.52 \mathrm{E}-02$ & 2.87 & $11 p 15.5$ & - \\
\hline 69 & miR-499-5p & $1.54 \mathrm{E}-02$ & 6.60 & $20 q 11.2$ & - \\
\hline 70 & $\operatorname{miR}-140$ & $1.58 \mathrm{E}-02$ & 2.35 & $16 q 22.1$ & - \\
\hline 71 & $\operatorname{miR}-188$ & $1.68 \mathrm{E}-02$ & 1.99 & Xp11.23 & $532-660$ \\
\hline 72 & miR-610 & $1.68 \mathrm{E}-02$ & 2.54 & $11 p 14.1$ & - \\
\hline 73 & $\operatorname{miR}-27 a$ & $1.70 \mathrm{E}-02$ & 2.45 & $19 p 13.12$ & $24-23 a$ \\
\hline 74 & miR-142-5p & $1.70 \mathrm{E}-02$ & 2.47 & $17 q 22$ & - \\
\hline 75 & miR-603 & $1.75 \mathrm{E}-02$ & 1.80 & 10p12.2 & - \\
\hline 76 & $\operatorname{miR}-660$ & $1.75 \mathrm{E}-02$ & 2.13 & Xp11.23 & $532-502$ \\
\hline 77 & $\operatorname{miR}-19 a$ & $1.75 \mathrm{E}-02$ & 2.79 & $13 q 31.3 / X q 26.2$ & $17-92 / 106 a-363$ \\
\hline 78 & miR-649 & $1.78 \mathrm{E}-02$ & 1.91 & $22 q 11.21$ & - \\
\hline 79 & miR-140-3p & $1.98 \mathrm{E}-02$ & 2.12 & $16 q 22.1$ & - \\
\hline 80 & $\operatorname{miR}-300$ & $2.00 \mathrm{E}-02$ & 2.30 & $14 q 32.31$ & $543-655$ \\
\hline 81 & $\operatorname{miR}-335$ & $2.11 \mathrm{E}-02$ & 2.11 & $7 q 32.2$ & - \\
\hline 82 & miR-206 & $2.20 \mathrm{E}-02$ & 1.84 & $6 p 12.2$ & $206-133 b$ \\
\hline 83 & miR-20b & $2.20 \mathrm{E}-02$ & 2.18 & $13 q 31.3 / X q 26.2$ & $17-92 / 106 a-363$ \\
\hline 84 & miR-130b & $2.25 \mathrm{E}-02$ & 2.19 & $22 q 11.21$ & $301 b-130 b$ \\
\hline 85 & miR-183 & $2.40 \mathrm{E}-02$ & 2.50 & $7 q 32.2$ & 183-182 \\
\hline 86 & $\operatorname{miR}-652$ & 2.44E-02 & 2.36 & $X q 22.3$ & - \\
\hline 87 & $\operatorname{miR}-133 b$ & $2.44 \mathrm{E}-02$ & 2.41 & $6 \mathrm{p} 12.2$ & 133b-206 \\
\hline 88 & $\operatorname{miR}-191^{*}$ & $2.56 \mathrm{E}-02$ & 1.97 & $3 p 21.31$ & 425-191 \\
\hline 89 & $m i R-19 b$ & $2.58 \mathrm{E}-02$ & 2.62 & 13q31.3/Xq26.2 & 17-92/106a-363 \\
\hline 90 & miR-212 & $2.71 \mathrm{E}-02$ & 1.97 & $17 p 13.3$ & $212-132$ \\
\hline 91 & miR-194 & $2.73 \mathrm{E}-02$ & 2.09 & $1 q 41 / 11 q 13.1$ & 215-194/192-194 \\
\hline 92 & $\operatorname{miR}-100$ & $2.82 \mathrm{E}-02$ & 2.82 & $11 q 24.1$ & 100-let7a \\
\hline 93 & miR-1234 & $2.88 \mathrm{E}-02$ & 1.91 & $8 q 24.3$ & - \\
\hline 94 & miR-182 & 2.96E-02 & 2.29 & $7 q 32.2$ & 183-182 \\
\hline 95 & miR-888 & $3.28 \mathrm{E}-02$ & 2.15 & $5 q 33.1$ & - \\
\hline 96 & $m i R-30 e-5 p$ & $3.55 \mathrm{E}-02$ & 2.27 & $1 \mathrm{p} 34.2$ & $30 e-30 c$ \\
\hline 97 & $\operatorname{miR}-574$ & $3.60 \mathrm{E}-02$ & 2.16 & $4 p 14$ & - \\
\hline 98 & $\operatorname{miR}-135 b$ & $3.60 \mathrm{E}-02$ & 2.31 & $1 q 32.1$ & - \\
\hline 99 & $\operatorname{miR}-125 b$ & $3.60 \mathrm{E}-02$ & 2.43 & $11 q 24.1 / 21 q 21$ & - \\
\hline 100 & miR-502 & 3.77E-02 & 1.79 & Xp11.23 & $500-502$ \\
\hline 101 & miR-320 & 3.77E-02 & 1.74 & $8 p 21.3$ & - \\
\hline
\end{tabular}


Table 1 MicroRNAs differentially expressed $(P$ ?<? 0.05) between MM $(n=33)$ and controls $(n=9)$ depicting chromosomal location and where relevant their expression within a microRNA cluster. (Continued)

\begin{tabular}{|c|c|c|c|c|c|}
\hline 102 & $m i R-421$ & $3.77 \mathrm{E}-02$ & 1.76 & $X q 13.2$ & $421-374 b$ \\
\hline 103 & miR-129-3p & $3.77 \mathrm{E}-02$ & 1.80 & 7q32.1/11p11.2 & - \\
\hline 104 & miR-190b & 4.03E-02 & 2.02 & $1 \mathrm{q} 21.3$ & - \\
\hline 105 & miR-18a & 4.44E-02 & 2.21 & $13 q 31.3 / X q 26.2$ & 17-92/106a-363 \\
\hline 106 & miR-549 & 4.44E-02 & 2.25 & $15 q 25.1$ & - \\
\hline 107 & $m i R-338-5 p$ & 4.45E-02 & 1.97 & $17 q 25.3$ & $338-657$ \\
\hline 108 & $m i R-576-3 p$ & 4.60E-02 & 4.80 & $4 q 25$ & - \\
\hline 109 & miR-133a & $4.62 \mathrm{E}-02$ & 2.32 & $6 p 12.2$ & 133b-206 \\
\hline-1 & $\operatorname{miR}-373^{*}$ & 1.39E-03 & -1.82 & $19 q 13.42$ & $371-373$ \\
\hline-2 & $\operatorname{miR}-378^{*}$ & $2.43 \mathrm{E}-03$ & -3.34 & $5 q 33.1$ & - \\
\hline-3 & miR-143 & 8.83E-03 & -1.80 & $5 q 33.1$ & - \\
\hline-4 & $\operatorname{miR}-15 a$ & $1.51 \mathrm{E}-02$ & -1.67 & $13 q^{14}$ & $15 a-16$ \\
\hline-5 & miR-337 & $1.52 \mathrm{E}-02$ & -1.65 & $14 q 32.2$ & $493-432$ \\
\hline-6 & $\operatorname{miR}-223$ & $1.54 \mathrm{E}-02$ & -3.82 & $X q 12$ & - \\
\hline-7 & miR-369-3p & $1.55 \mathrm{E}-02$ & -1.83 & $14 q 32.31$ & $323-656$ \\
\hline-8 & miR-520g & $1.58 \mathrm{E}-02$ & -1.90 & $19 q 13.42$ & $517-518$ \\
\hline-9 & miR-485-5p & $1.75 \mathrm{E}-02$ & -3.18 & $19 q 13.42$ & $517-518$ \\
\hline-10 & $\operatorname{miR}-524^{*}$ & $1.86 \mathrm{E}-02$ & -1.83 & $19 q 13.42$ & $517-518$ \\
\hline-11 & miR-520h & 2.20E-02 & -1.98 & $19 q 13.42$ & $517-518$ \\
\hline-12 & miR-516-3p & $2.20 \mathrm{E}-02$ & -1.81 & $19 q 13.42$ & $517-518$ \\
\hline-13 & miR-519d & 2.20E-02 & -1.78 & $19 q 13.42$ & 517-518 \\
\hline-14 & miR-371-3p & $2.34 \mathrm{E}-02$ & -3.58 & $19 q 13.42$ & $517-518$ \\
\hline-15 & miR-455 & $2.88 \mathrm{E}-02$ & -1.88 & $9 q 32$ & - \\
\hline-16 & miR-520b & 2.96E-02 & -1.85 & $19 q 13.42$ & $517-518$ \\
\hline-17 & miR-518d & $3.28 \mathrm{E}-02$ & -2.09 & $19 q 13.42$ & $517-518$ \\
\hline-18 & miR-624 & $3.28 \mathrm{E}-02$ & -1.56 & $14 q 12$ & - \\
\hline-19 & miR-296 & 3.59E-02 & -1.85 & $21 \mathrm{q} 22.12$ & - \\
\hline-20 & miR-16 & 4.69E-02 & -1.83 & $13 q 14$ & $15 a-16$ \\
\hline
\end{tabular}

Positive values are up-regulated in MM and negative values down-regulated. MicroRNAs in common with Zhou et al [11] are denoted in red font and Pichiorri et al [12] in bold font.

aberrantly expressed in MGUS samples $(P<0.05$; Additional file 1 Table S3); 28 microRNAs were up-regulated and 11 down-regulated. Nine of these were consistent with a previous study [12], including up-regulation of $m i R-21$, the most up-regulated microRNA identified (10.3 fold change; Figure 2A), $m i R-222$ and $m i R-342$ (Figure 2E, $\mathrm{H}$ respectively), and down-regulation of $m i R$-200b (Figure 2F). Expression levels of MGUS-associated microRNAs distinguished between MGUS and controls by cluster analysis (Additional file 1 Figure S2), and correctly predicted $12 / 13(92 \%)$ the presence of this disorder by SVM analysis.

\section{Different genetic subtypes of MM have distinct microRNA} expression profiles

Recently it has become increasingly clear that MM displays an enormous genomic complexity that underlies the clinical heterogeneity observed with this disease. The presence of recurrent chromosomal abnormalities such as IgH translocations and $\operatorname{del}(13 \mathrm{q})$ have been shown to have prognostic significance in multiple studies and as a consequence cytogenetic classification is increasingly being used to stratify MM patients in clinical practice although not yet routinely $[15,16]$. In order to investigate microRNA expression in the different genetic subtypes of MM, twenty-six cases (for which there was sufficient material) were cytogenetically classified using the micro-FISH technique [17]. Individual patient karyotype data are summarized in Additional file 1 Table S1. Fourteen of 26 (54\%) of MM cases harbored an IgH translocation and 7/26 (27\%) exhibited the 13q $(R B)$ deletion. Of the translocation group eight (57\%) displayed the $\mathrm{t}(11 ; 14)$ translocation, three $(21 \%)$ cases the $\mathrm{t}(4 ; 14)$ translocation, and three cases had an $\operatorname{IgH}$ translocation with an un-known (tested) fusion partner. Ten (38\%) MM patients had no detectable chromosomal abnormality using our FISH probe sets, although it is probable that these cases had undetected abnormalities.

The majority of MM tumors harbor IgH translocations, the most common fusion partners being $11 \mathrm{q} 13$ 


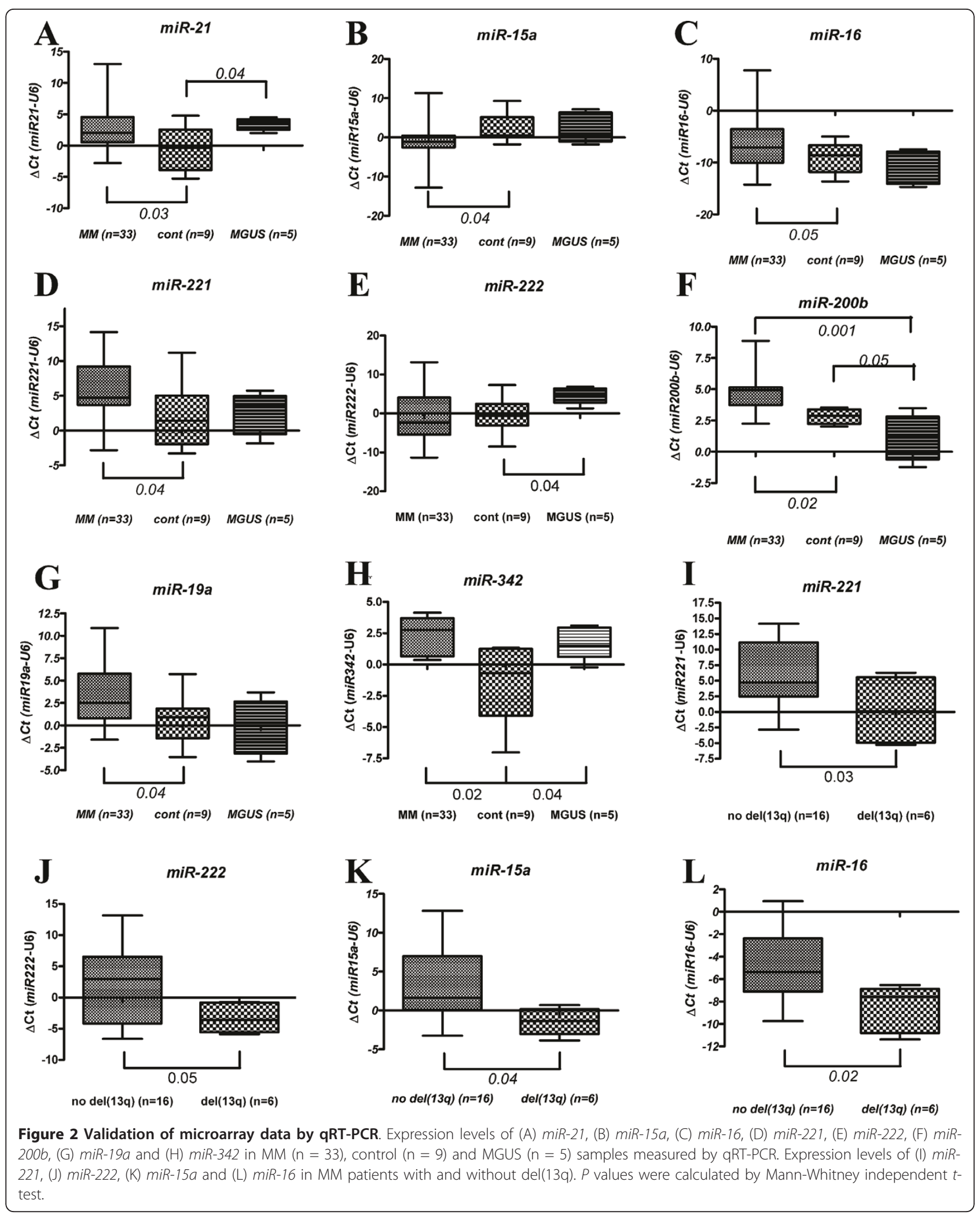


(CCND1) and 4p16 (FGFR3) [18]. A comparison between cases containing an IgH translocation with those that did not identified seven differentially expressed $(\mathrm{P}<0.05)$ microRNAs (Table 2$)$. Expression levels were distinct in MM cases containing the $\mathrm{IgH}$ translocation (Figure 3A), and predicted 24/26 (92\%) of cases by SVM analysis. Seventeen microRNAs were identified as being associated with the most common IgH translocation event, $\mathrm{t}(11 ; 14)(\operatorname{IgH}: C C N D 1)(\mathrm{P}<$ 0.05 ; Table 2), four of which $(m i R-375, m i R-650, m i R-$ $193 a$ and $m i R-582)$ were consistent with other studies $[19,20]$. Expression levels of these microRNAs distinguished cases with $\mathrm{t}(11 ; 14)$ (Figure $3 \mathrm{~B}$ ), and correctly predicted the presence of this translocation in 24/26 (92\%) of cases by SVM analysis. Three cases in our cohort had the $\mathrm{t}(4 ; 14)$ (IgH:FGFR3) translocation. Eight microRNAs were associated with this translocation $(\mathrm{P}<$ 0.05 ; Table 2), three of which (miR-99b, $m i R-342$ and $m i R-214)$ were previously identified $[19,20]$. Expression levels of these microRNAs distinguished cases with the $t$ $(4 ; 14)$ translocation (Figure 3C) and correctly predicted all cases containing this translocation. Interestingly, four of the six up-regulated microRNAs are encoded on either chromosome 4 or 14 ( $m i R-376 a(14 \mathrm{q} 33.21)$, $m i R$ 342 (14q32.2), miR-574 (4p14) and miR-577 (4q26)), and of the two microRNAs ( $m i R-520 c$ and $m i R-376 a)$ aberrantly expressed in both $\mathrm{t}(4 ; 14)$ and $\mathrm{t}(11 ; 14)$ cases, the latter is encoded proximal to the IgH breakpoint region at $14 \mathrm{q} 32$.

A comparison between microRNA expression in del (13q) MM patients with patients not harboring this deletion identified 28 microRNAs by ANOVA $(P<0.05$; Table 2). Expression levels of these microRNAs distinguished cases that were $\operatorname{del}(13 q)$ by cluster analysis (Figure 3D), and correctly predicted its presence in $22 / 26$ (85\%) of cases by SVM analysis. Eight of these microRNAs were consistent with research by Gutiérrez and colleagues [19], including down-regulation of $m i R-15 a$ and $m i R-16$, encoded within the 13q14 locus (Figure $2 \mathrm{~K}$ and $2 \mathrm{~L}$ respectively).

\section{MicroRNA expression is associated with clinical parameters and survival}

The most common paraprotein isotypes associated with MM are IgG (60\%) and IgA (24\%) [21]. It has been reported that IgA myeloma has a poorer prognostic outcome than patients with IgG myeloma [22], although it should be noted that we (data not shown) and others [23] did not find any survival differences between isotypes. Consequently we compared expression levels between thirteen cases of IgG-type MM with eight cases of IgA-type. This resulted in the identification of twenty-one differentially expressed microRNAs $(P<$ 0.05; Additional file 1 Table S5). Expression levels of these microRNAs were distinct between IgA and IgG MM cases (Additional file 1 Figure S4), and correctly predicted isotype for 20/21 (95\%) of cases by SVM analysis.

Approximately $10 \%$ of MM patients secrete only light chains instead of the complete immunoglobulin molecule [21]. So called "light chain only myeloma" or "Bence Jones myeloma" had been reported to have a poorer prognostic outcome [22,24] although a more recent (and comprehensive) study found no such difference [23]. In our cohort eight MM cases had light chain only myeloma. Twenty-seven microRNAs were identified as being differentially expressed compared to nonlight chain only MM cases (Additional file 1 Table S6). Expression levels of these microRNAs correctly predicted light-chain only myeloma in all cases.

As we had successfully identified microRNAs associated with clinical outcome in diffuse large B-cell lymphoma [7], we assessed differences in microRNA expression between poor outcome and good outcome in MM cases, using event-free survival (EFS) as our clinical criterion (median follow-up $=20$ months). Samples from patients with event-free survival $(n=21)$ were contrasted with those from patients who had relapsed or died in this interval $(n=7)$. Thirty-two microRNAs were identified as being differentially expressed $(\mathrm{P}<$ 0.05) (Additional file 1 Table S7). These microRNAs correctly predicted relapse in $24 / 28$ (86\%) of cases by SVM analysis. To investigate the effect of individual microRNA expression levels on clinical outcome we carried out log-rank (univariate) survival analysis and found that low expression of $m i R-153, m i R-490, m i R-455$, $m i R-$ 642, $m i R-500$, and $m i R-296$, and high expression of $m i R-$ $548 d$, $m i R-373, m i R-554$ and $m i R-888$ were associated $(P$ $<0.05$ ) with EFS (Figure 4).

\section{Discussion}

In this study we used microarray technology to elucidate the complete miRNome (miRBase version 13.0) of purified PCs from $33 \mathrm{MM}$ and 5 MGUS patients and compared their expression with counterpart normal PCs. One hundred and twenty-nine microRNAs were identified as being aberrantly expressed in MM. Thirty-nine (30\%) of these were previously reported to be aberrantly expressed in MM by Pichiorri et al [12] and/or Zhou et al [11]. The reason for these discrepancies probably reflects the use of differing statistical, microarray and sampling methods. Of note the former study only examined $10 \mathrm{MM}$ and 4 controls, whilst the latter study included only 2 controls for analysis. Consistent with the findings of Pichiorri and colleagues we found that miR-21 was up-regulated in both MM and MGUS as were all seven microRNAs encoded by $m i R-17-92$ cluster (average fold-change $=2.1$; range $1.75-2.78$ ) 
Table 2 MicroRNAs associated $(P<0.05)$ with different genetic subtypes depicting chromosomal location.

\begin{tabular}{|c|c|c|c|c|}
\hline Cytogenetic group & microRNA & Fold change & $P$-value & Chromosome \\
\hline \multirow[t]{7}{*}{ IgH trans $(n=14)$} & miR-590 & 3.28 & $1.62 \mathrm{E}-02$ & $7 q 11.23$ \\
\hline & miR-886 & 1.63 & $1.46 \mathrm{E}-02$ & $5 q 31.1$ \\
\hline & $m i R-33 b$ & 1.48 & $2.46 \mathrm{E}-02$ & $17 p 11.2$ \\
\hline & miR-184 & -1.43 & $3.87 \mathrm{E}-02$ & $15 q 25.1$ \\
\hline & $\operatorname{miR}-139$ & -1.44 & $1.47 \mathrm{E}-02$ & $11 q 13.4$ \\
\hline & miR-508 & -1.63 & $4.55 \mathrm{E}-03$ & $X q 27.3$ \\
\hline & $\operatorname{miR}-579$ & -1.66 & $2.43 \mathrm{E}-02$ & $5 p 13.3$ \\
\hline \multirow[t]{17}{*}{$t(11 ; 14)(n=8)$} & $\operatorname{miR}-202^{*}$ & 2.16 & $3.10 \mathrm{E}-03$ & $10 \mathrm{q} 26.3$ \\
\hline & miR-520c & 2.05 & $1.26 \mathrm{E}-03$ & $19 q 13.42$ \\
\hline & miR-890 & 2.04 & 4.39E-02 & $X q 27.3$ \\
\hline & $\operatorname{miR}-582$ & 1.91 & 4.06E-02 & $5 q 12.1$ \\
\hline & miR-122a & 1.88 & $1.40 \mathrm{E}-02$ & $3 p 21.31$ \\
\hline & $\operatorname{miR}-526 b^{*}$ & 1.86 & $1.09 \mathrm{E}-04$ & $19 q 13.42$ \\
\hline & $\operatorname{miR}-375$ & -1.74 & $2.04 \mathrm{E}-02$ & $2 q 35$ \\
\hline & $\operatorname{miR}-543$ & -1.59 & $3.46 \mathrm{E}-02$ & $14 q 33.21$ \\
\hline & $\operatorname{miR}-650$ & -1.58 & 4.00E-02 & $22 q 11.22$ \\
\hline & miR-193a & -1.51 & $1.35 \mathrm{E}-02$ & $17 q 11.2$ \\
\hline & miR-147b & -1.46 & $2.76 \mathrm{E}-02$ & $15 q 21.1$ \\
\hline & miR-526a & -1.51 & $4.68 \mathrm{E}-02$ & $19 q 13.42$ \\
\hline & miR-542 & -1.56 & $1.81 \mathrm{E}-02$ & $X q 26.3$ \\
\hline & miR-301 & -2.22 & 4.80E-02 & $17 q 22$ \\
\hline & miR-26b & -2.62 & $3.81 \mathrm{E}-02$ & $2 q 35$ \\
\hline & miR-376a & -2.63 & $2.68 \mathrm{E}-02$ & $14 q 33.21$ \\
\hline & $\operatorname{miR}-21$ & -2.82 & 5.19E-03 & $17 q 23.1$ \\
\hline \multirow[t]{8}{*}{$t(4 ; 14)(n=3)$} & $\operatorname{miR}-376 a$ & 3.48 & $1.23 \mathrm{E}-02$ & $14 q 33.21$ \\
\hline & miR-574 & 3.11 & $1.23 \mathrm{E}-02$ & $4 p 14$ \\
\hline & miR-99a & 2.53 & $1.23 \mathrm{E}-02$ & $21 q 21.1$ \\
\hline & miR-214 & 2.12 & 2.77E-02 & $1 \mathrm{q} 24.3$ \\
\hline & miR-577 & 1.97 & $3.85 \mathrm{E}-02$ & $4 q 26$ \\
\hline & $\operatorname{miR}-342$ & 1.79 & $3.50 \mathrm{E}-02$ & $14 q 32.2$ \\
\hline & miR-935 & -2.07 & $3.55 \mathrm{E}-02$ & $19 q 13.42$ \\
\hline & miR-520c & -2.23 & $3.85 \mathrm{E}-02$ & $19 q 13.42$ \\
\hline \multirow[t]{19}{*}{$13 q($ del $)(n=6)$} & $m i R-221$ & -9.71 & $1.18 \mathrm{E}-04$ & Xp11.3 \\
\hline & miR-222 & -9.50 & $1.78 \mathrm{E}-03$ & Xp11.3 \\
\hline & let-7b & -5.15 & $3.38 \mathrm{E}-03$ & $22 q 13.31$ \\
\hline & let-7a & -4.92 & $3.72 \mathrm{E}-03$ & $9 q 22.32 / 11 q 24$ \\
\hline & let-7c & -4.86 & $6.70 \mathrm{E}-03$ & $21 \mathrm{q} 21.1$ \\
\hline & $m i R-15 a$ & -4.42 & $6.39 \mathrm{E}-03$ & $13 q^{14}$ \\
\hline & $m i R-20 a$ & -4.41 & $1.47 \mathrm{E}-03$ & $13 q 31$ \\
\hline & miR-107 & -4.40 & $3.23 \mathrm{E}-03$ & $10 \mathrm{q} 23.31$ \\
\hline & miR-26a & -4.37 & $3.26 \mathrm{E}-03$ & $3 p 22.2 / 12 q 14.1$ \\
\hline & miR-103 & -4.30 & 8.98E-03 & $5 q 34 / 20 p 13$ \\
\hline & miR-142 & -4.13 & $1.15 \mathrm{E}-03$ & $17 q 22$ \\
\hline & miR-195 & -3.97 & $6.98 \mathrm{E}-03$ & 17p13.1 \\
\hline & miR-146a & -3.92 & $1.46 \mathrm{E}-03$ & $5 q 33.3$ \\
\hline & miR-23a & -3.80 & $6.44 \mathrm{E}-03$ & $19 p 13.12$ \\
\hline & miR-92a & -3.77 & $3.57 \mathrm{E}-03$ & $13 q 31$ \\
\hline & miR-27a & -3.58 & $2.25 \mathrm{E}-03$ & $19 p 13.12$ \\
\hline & miR-361 & -3.46 & 4.19E-03 & $\mathrm{Xq} 21.2$ \\
\hline & miR-145 & -3.43 & 7.10E-03 & $5 q 32$ \\
\hline & miR-92b & -3.37 & $9.82 \mathrm{E}-03$ & $13 q 31$ \\
\hline
\end{tabular}




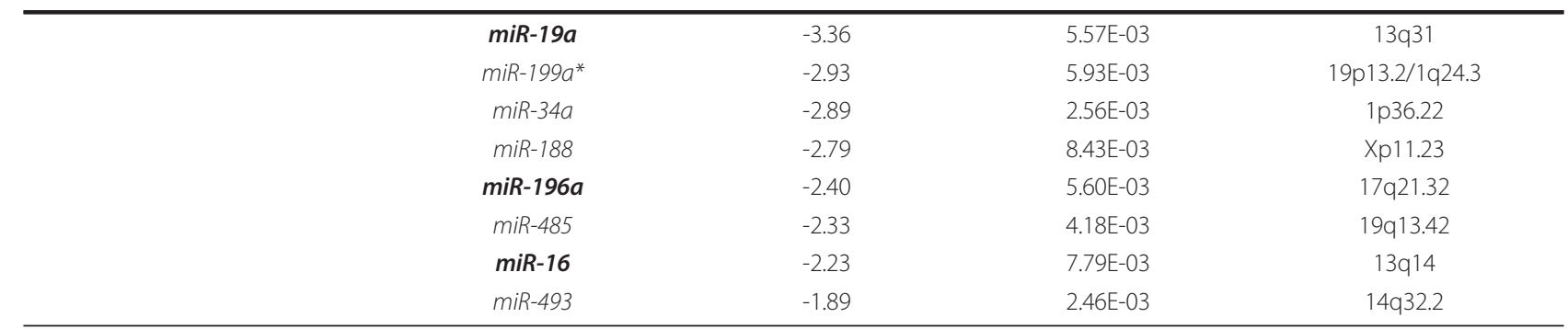

Comparison between MM cases with (positive fold change) and without (negative fold change) chromosomal abnormality as indicated in text. MicroRNAs also identified by Gutiérrez et al [19] or Lionetti et al [20] are depicted in bold type.

However unlike that study, although $m i R-32$ and $m i R$ $181 a$ were identified as being up-regulated by microarray analysis, we failed to find any significant difference in expression levels by qRT-PCR (data not shown). Surprisingly 10 of the 20 down-regulated microRNAs identified in the current study are encoded by the miR-3711323 cluster located at $19 \mathrm{q} 13.42$. This cluster consists of 49 microRNAs, 39 of which were present on our microarray. All members of this cluster were down-regulated (average 1.6-fold; range 1.1-2.5). Interestingly, members of this cluster (miR-373 and $m i R-520 c)$ have been demonstrated to be associated with tumor invasion and metastasis [25].

The vast majority (109/129 (85\%)) of microRNA aberrantly expressed in MM were up-regulated, consistent with the findings of Zhou et al [11]. We [7,26] (and others[27]) found the same pattern in other B-cell malignancies. In contrast, we [10] (and others [28]) recently demonstrated that $\mathrm{T}$-cell malignancies are associated with a global decrease in microRNA expression. This suggests a fundamental difference in microRNA biogenesis between $\mathrm{B}$ and T-cell malignancies. A possible explanation for this distinction comes from our previous observation that components of the microRNA biosynthetic pathway (i.e. the microprocessor complex (DGCR8 and Drosha)) are up-regulated in B-cell malignancies (including MM) but down-regulated in T-cell malignancies [29].

Using the same array as in this study, we previously identified 60 and 119 microRNAs aberrantly expressed in diffuse large B-cell lymphoma (DLBCL) [7] and Sézary syndrome (SzS) (T-cell lymphoma) respectively [10]. A comparison with MM-associated microRNAs revealed that $25 / 60(42 \%)$ and $47 / 119(40 \%)$ of microRNAs

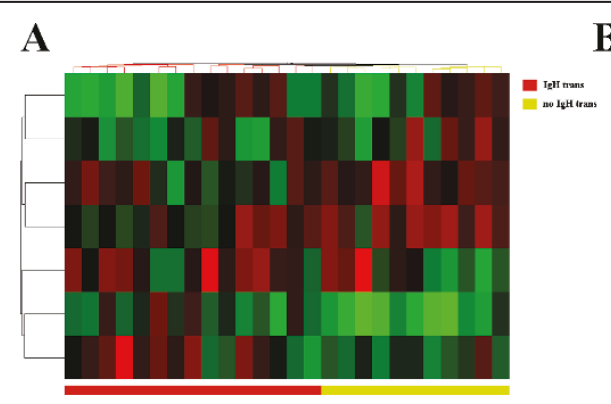

B

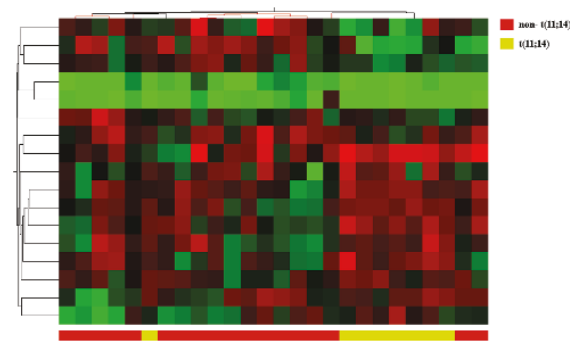

C

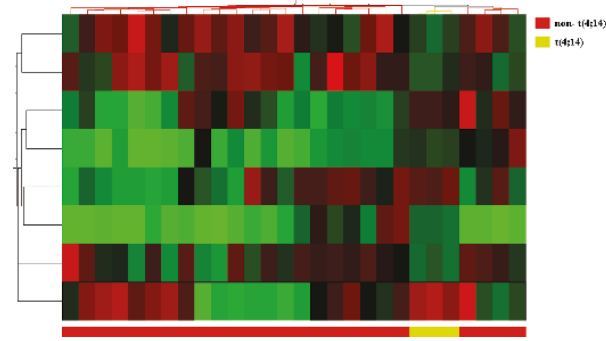

D

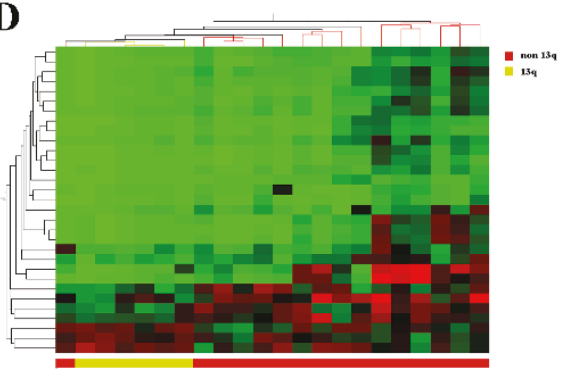

Figure 3 MicroRNA expression can distinguish between different genetic subtypes of MM. Cluster analysis heat maps depicting expression levels of microRNAs associated with (A) IgH translocation, (B) $t(11 ; 14)$, (C) $t(4 ; 14)$ and (D) del(13q). 

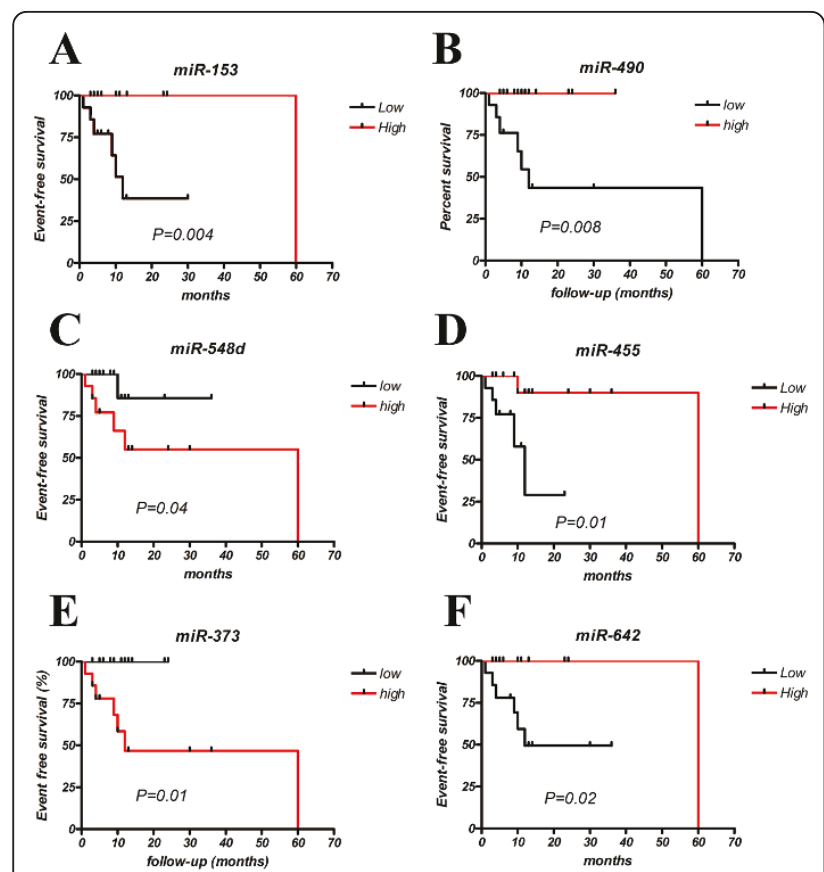

G
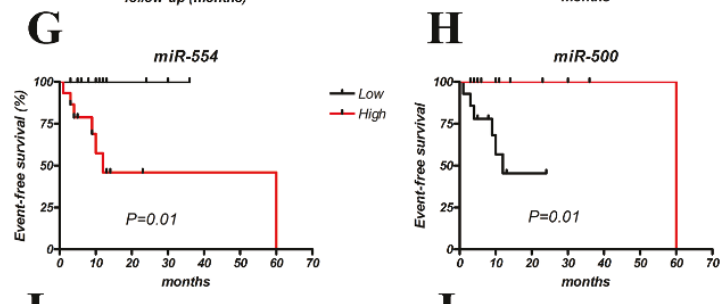

亡 Low
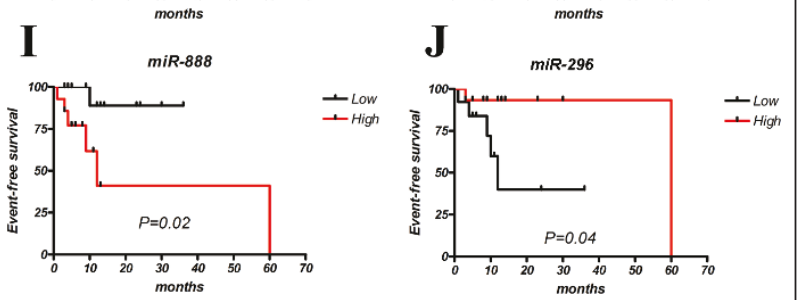

Figure 4 Kaplan-Meier survival curves of EFS in MM patients based on high or low (median) expression levels of microRNAs $(P<0.05)$. Curves were compared by univariate (logrank) analysis. (A) miR-153, (B) miR-490, (C) miR-548d, (D) miR-455, (E) miR-373, (F) miR-642, (G) miR-554, (H) miR-500, (I) miR-888 and (J) miR-575.

aberrantly expressed in DLBCL and SzS respectively were also aberrantly expressed in MM (Figure 5 andAdditional file 1 Table S2). Fourteen microRNAs were dysfunctionally expressed in all three lymphoma types with miR-223 and miR-143 commonly down-regulated and miR-574 commonly up-regulated. Although this analysis is by no means exhaustive this suggests the presence of a common lymphoma microRNA signature. Down-regulation of miR-223 also has been demonstrated in hepatocellular carcinoma [30], acute myeloid leukemia [31] and chronic lymphocytic leukemia [32,33], and shown to regulate the important hematopoietic regulator LMO2 [34] that is commonly expressed in lymphoma

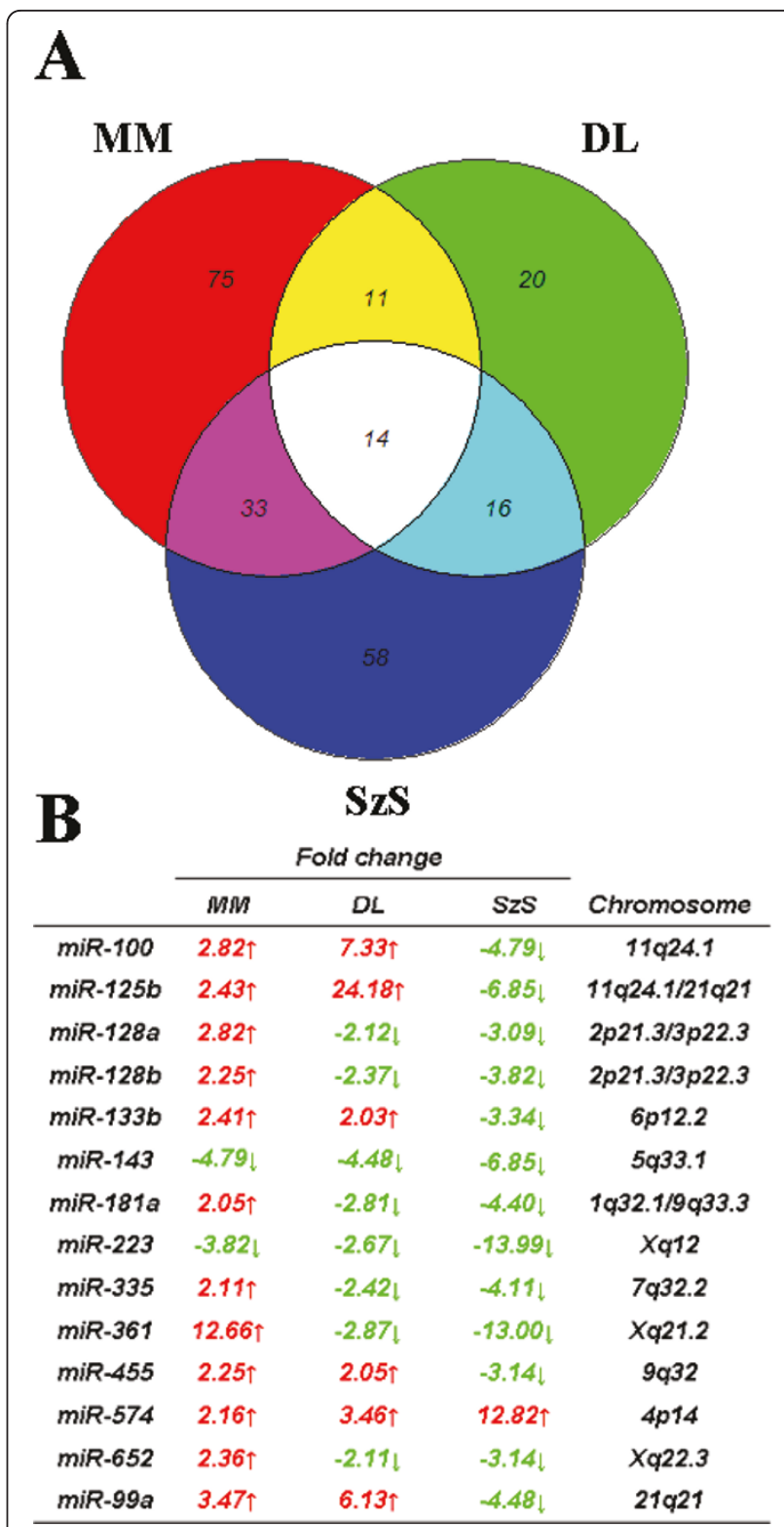

Figure 5 MicroRNAs commonly dysfunctionally expressed in multiple lymphoma types. (A) Venn diagram showing relationship between microRNAs aberrantly expressed in diffuse large B-cell lymphoma (DLBCL) [7], Sezary syndrome (SzS) [10] and multiple myeloma (MM) ((Table 1) (Additional file 1, Table S2)). (B) Tables of microRNAs aberrantly expressed in all lymphoma types depicting fold change relative to normal counterpart controls.

[35]. Similarly, miR-143 has been reported to be commonly down-regulated in hematological malignancy [36]. We are currently investigating expression of these microRNAs in a range of lymphoma types to see if their dysregulation is truly a common feature of lymphoma.

MGUS has been shown to consistently proceed the development of MM [37] and as such is considered to represent a pre-malignant model for MM pathogenesis. 
Twenty-three of the 39 (59\%) microRNAs aberrantly expressed in MGUS were also aberrantly expressed in MM (Additional file 1 Table S3) suggesting common microRNA expression events in MM progression. Thirty-seven microRNAs were identified as being differentially expressed between MGUS and MM (Additional file 1 Table S4), only 9 of these were also differentially expressed in MGUS compared to controls (i.e. specific for MGUS) including $m i R-21$ as previously identified [12]. The relationship between microRNAs dysfunctionally expressed in MGUS and MM are shown in Additional file 1 Figure S3. miR-21 over-expression has been linked to an anti-apoptotic phenotype and enhanced tumor growth $[38,39]$ and as such may represent an important aberration in the early pathogenesis of MM.

Next we investigated the identity of microRNAs associated with the major genetic subtypes of MM. Two previous studies by Lionetti et al [20] and Gutiérrez et al [19] have also examined microRNA expression associated with recurrent chromosomal abnormalities in MM. Generally our findings were consistent with these studies although microRNAs associated with specific abnormalities did not always completely overlap. The cause for discrepancies between studies, including lack of concordance between the two previously published studies, again probably represents differences between microarray platforms, statistical techniques and samples used for analysis. For example the study of Gutiérrez et al considered cases in which del(13q) was the sole chromosomal abnormality and deregulated microRNAs were identified on the basis of their expression relative to control PCs, whereas our study and that of Lionetti et al considered the difference between MM cases with and without specific chromosomal abnormalities $[19,20]$. The latter study considered genetic abnormalities in the context of a gene-expression defined molecular translocation/cyclin (TC) classification system [20]. Such differences between studies are a reflection of the relative immaturity of the microRNA field that has only formally existed for the last 9 years, and is something that will surely be resolved in future years.

Interestingly, from the 28 microRNAs associated with the presence of $\operatorname{del}(13 \mathrm{q})$, all seven microRNAs encoded by the miR-17-92 cluster (encoded at 13q31) were down-regulated (average 3.1 fold; range 1.2-4.1). Recent data suggests that unlike the characteristic del(13q) karyotype observed in chronic lymphocytic leukemia (CLL) defined by loss of the 13q14 locus, the minimal deleted region of 13q loss in MM extends from 13q14 to the 13q34 locus [40], consistent with down-regulation of the miR-17-92 cluster observed in these cases. Although down-regulation of the miR-17-92 cluster was also reported by Gutiérrez et al [19], this finding is counterintuitive as members of this cluster are widely believed to function as oncogenes [41] whilst the presence of del (13q) is associated with an adverse prognostic outcome in MM [42]. A possible explanation for this apparent paradox is that although widely up-regulated in a wide range of cancers $[9,26,43]$, the $m i R-17-92$ cluster has been proposed to act as both tumor-suppressor or oncogene depending upon the cellular context [44-46]. Recently we reported that this cluster is down-regulated in T-cell lymphoma where it was shown to have tumorsuppressor properties [10]. Consequently, it is possible that the cluster is similarly acting as a tumor-suppressor in $\operatorname{del}(13 q) M M$ cases although it should be noted that up-regulation of this cluster is associated with MM diagnosis (Table 1) and at least one member of this cluster (miR-19) was found to antagonize MM tumor development in a murine model [12].

We also report for the first time a correlation between microRNA expression and isotype in MM including the presence of light-chain only myeloma. Such information might be useful in providing an alternative clinical classification of new MM patients. Finally, we examined how the expression levels of individual microRNAs might influence clinical outcome of MM patients by correlating expression values with adverse effects using Kaplan-Meier survival analysis. We found that high expression of $m i R-153$, miR-490, miR-455, miR-642, miR-500, and miR-296 were associated with better EFS in our cohort of patients whilst the opposite was true for $m i R-548 d$, $m i R-373$, miR-554 and miR-888. Interestingly, the most discriminatory of these microRNAs (i.e. miR-153) has been shown to target BCL2 and MCL1 [47] and that over-expression of both of these are associated with poor prognostic outcome in MM [48]. Low expression of $m i R-455$ has also been associated poor overall survival in endometrial serous adenocarcinoma [49], and low levels of $m i R-296$ shown to be associated with increased prostate tumor growth and invasion properties via targeting of HMGA [50]. It should be noted however that these data need to be tested in an independent test cohort before any firm conclusions can be drawn about the prognostic ability of these microRNAs in MM patient survival, whilst the current results provide the experimental basis for future validation experiments.

\section{Conclusions}

In summary, these results indicate that aberrant expression of microRNAs is a common feature of MM as well as pre-malignant MGUS, and that this phenomenon is associated with genetic and clinical subtype as well as clinical outcome. This data reinforces the complex nature of MM and hopefully will provide useful information in clarifying the molecular basis of this disease in future studies. 


\section{Methods}

\section{Patient samples and cell lines}

Bone marrow samples were obtained from patients attending the Department of Haematology, John Radcliffe Hospital, Oxford, UK or Dubrava University hospital Zagreb, Croatia. Patients were diagnosed as MM (n = 33) or MGUS $(n=5)$ according to criteria described in the myeloma management guidelines [51]. The median age of patients was 67 yrs (range 43-89 yrs). Individual patient details are shown in Additional file 1 Table $\mathrm{S} 1$. Plasma cells (PC) were purified from bone marrow aspirates by positive immunomagnetic selection (CD138 ${ }^{+}$) according to manufacturer's instructions (Miltenyi Biotec, Bisley, UK). PCs obtained from the bone marrow of nine healthy individuals were used as controls. The purity of PC samples was $>90 \% \mathrm{CD} 138^{+}$as measured by immunohistochemical staining.

Patient samples were collected in accordance with the Declaration of Helsinki and approved by the local ethics committee (Oxforshire Regional Ethics Committee; Ref no. 07/Q1606/25). Patients gave written informed consent for the sample collection.

MM cell lines, NCI-H929, JJN3, RPMI8226 and Thiel were routinely cultured in RPMI 1640 containing 10\% fetal calf serum (Invitrogen, Paisley, UK). All cell lines were obtained from the DSMZ cell collection (Braunschweig, Germany) except Thiel which was a kind gift from Prof. Diehl (University of Cologne, Germany).

\section{Cytogenetic classification of myeloma samples}

Purified MM patient PCs $\left(\sim 10^{5}\right.$ cells $)$ were classified according to cytogenetic criteria using the micro-FISH technique as previously described [17]. The following probe sets obtained from Vysis (Abbott Diagnostics, Maidenhead, UK) were used for classification; D13S319 Spectrum-Orange/LSI-13q34-Spectrum-Green (del(13q) probe), IgH Spectrum-Green/FGFR3 Spectrum-Orange $(\mathrm{t}(4 ; 14)$ fusion probe), IgH Spectrum-Green/CCND1 Spectrum-Orange $(t(11 ; 14)$ fusion probe), and IgH dualcolor (Spectrum-Green/Spectrum-Orange) break-apart probe [52]. At least 100 nuclei were scored for each probe. A $20 \%$ cut-off was used for numerical abnormalities and $10 \%$ for fusions and break-apart probes as recommended by the European Myeloma Network FISH workshop guidelines http://www.myeloma-europe.org.

\section{RNA purification and microarray analysis}

MicroRNA was isolated from samples $\left(\sim 10^{6}\right.$ cells $)$ using Trizol (Invitrogen, Paisley, UK) and RNeasy columns as described by the manufacturer (Qiagen, Crawley, UK). MicroRNA ( $500 \mathrm{ng})$ were labeled and hybridized to $\mu$ RNA microarrays as previously described [26] using tonsillar material (pooled from twelve healthy individuals) as a common reference in a dye-balanced design. The arrays contained 655 human probes (miRBase v.10.1). Probe details can be found at http://www.microRNAworld.com.

Image analysis was carried out with BlueFuse software (BlueGnome, Cambridge, UK). Raw image data were global loess-normalized within arrays and normalized between arrays using the LIMMA package [53]. The normalized log ratios (average of four replicates per probe) were used for subsequent analysis in Genespring 7.2 (Agilent Technologies, CA, US). ANOVA analysis was used to identify microRNAs differentially expressed between sample types and $P$ values were adjusted using the Benjamini-Hogberg correction method. Differentially expressed genes were tested for their ability to predict sample class using the leave-one-out cross-validation support vector machine (SVM) function in Genespring (Polynomial Dot Product (Order 1) Kernel Function. Diagonal Scaling Factor: 0). All microarray data was MIAME compliant and raw data has been deposited in the GEO database (Accession series \# GSE243371).

\section{Quantitative RT-PCR (qRT-PCR)}

MicroRNA qRT-PCR was carried out using Taqman probes as described by the manufacturer (Applied Biosystems, Warrington, UK) using $20 \mathrm{ng}$ of microRNA per reaction in a Roche LightCycler 480 machine. Triplicate samples were used throughout. The mean $\mathrm{Ct}$ value of each triplicate was used for analysis, by the $\Delta C_{t}$ method $\left(\Delta \mathrm{C}_{\mathrm{t}}=\right.$ mean $\mathrm{C}_{\mathrm{t}}$ of microRNA of interest-mean $\mathrm{C}_{\mathrm{t}}$ of U6). Expression levels were compared using Mann-Whitney independent $t$-test (Graphpad Prism v.4.0, La Jolla, CA).

\section{Survival analysis}

Kaplan-Meier survival analysis was carried out on event free survival (EFS) times of MM patients as a function of microRNA expression, using the median value as cutoff. EFS was calculated as the time of diagnosis to the date of clinical relapse, death or last contact. Patients who were relapse-free at time of last contact were censored for analysis. Mean follow-up time was 20 months (range 1-60 months). Curves were compared by univariate (logrank) analysis using GraphPad Prism version 4.00 (La Jolla, CA).

\section{Reviewers' comments}

Reviewer \#1: Prof. Neil Smalheiser, Department of Psychiatry, University of Illinois, Chicago, IL, US.

\section{Reviewer's comments}

This is a nice paper and I only have relatively minor comments, which can be addressed by page number: 
p. 2. It would not hurt to have some discussion of the miR expression in the control group, in terms of the cell type profile, heterogeneity across individuals, etc. If you included that, I missed it.

\section{Authors' response}

Whilst the reviewer has an interesting suggestion i.e. to look at variation in miRNA expression across the control group, the main theme of this research was to look at expression in multiple myeloma, therefore the number of controls samples used $(n=9)$ does not have sufficient power in order to address that specific question. However, our data does suggest that the control samples varied little in their miRNA expression profile as shown by unsupervised cluster analysis (Figure 1).

p. 2. You speak of altered miR expression in tumor cells as "aberrant" throughout the paper. Yet not every difference is necessarily aberrant. Some changes may be compensatory; some changes may simply reflect the physiological state of the tumor cells without being linked to tumorigenicity per se (e.g., they may differ in $\mathrm{O} 2$ tension or $\mathrm{pH}$ ).

\section{Authors' response}

We whole-heartedly agree that not all differentially expressed miRNAs identified in MM tumor cells will be directly linked with their neoplastic nature but instead may reflect indirect effects such as their abnormal microenvironment and/or interaction with non-tumor cells for example. We believe however that as these effects, direct and indirect, cumulatively represent tumor-associated changes in the miRNA expression profile of cells, that the use of the adjective 'aberrant' in this context is an accurate description of the expression behavior of miRNAs that are 'diverging from the normal' (Oxford Concise Dictionary).

p. 10 and Methods. It is worthwhile to describe the method of correcting p-values for multiple-testing in more detail.

\section{Authors' response}

As stated in the methods section p-values were corrected using the Benjamini-Hogberg multiple testing correction algorithm as implemented in the ANOVA function of the Genespring software package. This algorithm is based on false discovery rate error type and further details can be found in the original publication of this method (Benjamini and Hochberg (1995). Journal of the Royal Statistical Society B, 57, 289-300)). As this method is widely used in microarray analyses we believe that a more indepth and mathematical description of this method is not warranted for this manuscript.

p. 10 and throughout. The paper has a nice balance between considering miRs as a clinical tool and as an indication of tumor biology. However, you can go still further to analyze in biological terms WHY the pattern of altered miR expression is the way it is, or (stated a different way) to analyze what dimensions are most important for SVM prediction. For example, do the altered miRs all share the same TFs driving them?

\section{Authors' response}

The reviewer has raised a very important point about addressing the reason for aberrant miRNA expression in MM. However, the causal mechanisms behind miRNA dysregulation in any cancer are complex, although we did try to proffer some insight in the context of MM in both results and discussion sections of this manuscript. Possible mechanisms include chromosomal lesions at miRNA-encoding regions and defects in miRNA biosynthetic machinery, both of which were addressed in this manuscript. Further mechanisms include epigenetic regulation, changes in expression of genes such as E2F that can bind to promoter regions of pri-miRNA sequences, as well as any factor that can regulate levels of the proteinencoding genes that encode for $>40 \%$ of human miRNAs. The problem with identifying genes such as TFs that are potentially targeted by commonly differentially expressed miRNAs, is that currently the predictive algorithms to carry out this type of analysis perform very poorly (Sethupathy, et al (2006) Nat Methods, 3, 881-886). Therefore we believe that the robustness and hence usefulness of such an in silico approach is limited. Consequently we decided to restrict our discussion to those target genes that have been independently experimentally validated.

p. 13. You mention that dicer and drosha tend to be up-regulated in B-cell malignancies. It would be desirable to have measured these in the SAME samples reported here and see if dicer and/or drosha levels are tightly correlated with miR up-regulation.

\section{Authors' response}

This would be the ideal situation, and in the case of the $D L B C L$ case this comparison was carried out (Lawrie et al (2009) Br. J. Haematol., 145, 545-548). Unfortunately there was insufficient material left from the current study to carry out a similar analysis on the MM samples.

p. 19, Methods. Were control and tumor samples collected during the same period? stored for similar amounts of time? Assayed in parallel? If not, this could create confounds.

\section{Authors' response}

Due to the logistics of obtaining bone marrow samples from $\sim 50$ patients/controls it would have been extremely difficult to collect samples over the same period-samples were collected over a 2 year period from two centers (Oxford and Zagreb). Patient/control samples were assayed in parallel and randomized/anonymized to the researchers processing them in order to minimize confounding variables. 
p. 20, Methods. Was U6 expression the same in control and tumor samples? This should be stated explicitly. Authors' response

U6 levels were measured in controls and tumor in parallel using the same assay system (i.e. Taqman probe qRTPCR). There was no significant difference in absolute U6 expression levels (i.e. Ct values) between controls and tumor samples.

p. 29, Table 1. You have mir-200a listed twice with two different values?! Please check this (very long) table.

\section{Authors' response}

This was a mistake. Position 25 in Table 1should have read $m i R-200 a^{*}$ and not miR-200a, this has been corrected.

p. 35, Figure 3 Legend. Please spell out DL, MM and SZ

\section{Authors' response}

This issue has been addressed.

Reviewer \#2: Prof. Yuriy Gusev, Department of Surgery, University of Oklahoma, OK, USA.

This reviewer provided no comments for publication.

Reviewer \#3: Unknown reviewer

\section{Reviewer's comments}

This manuscript includes a description of microarray analysis for the expression of microRNA in purified CD138+ cells from 33 patients with multiple myeloma (MM), 5 patients with monoclonal gammopathy of undetermined significance (MGUS), and 9 healthy volunteers. The authors found distinct microRNA expression profiles from each group. Similar studies from 2 different groups have been reported. However, in one study only 16 samples from patients with MM, 6 from patients with MGUS, and 6 controls were included and in the another study samples from 52 patients but only 2 controls were studied. The manuscript is clear and concise. The data are convincing and the area of investigation is important. This manuscript is a valuable contribution. Specific comments follow:

1. The authors state several times that they have performed a comprehensive study to elucidate the complete miRNome of the CD138+ cells; however, I could not find how "complete" was defined. The manuscript would be improved by including a consideration about the completeness of the analysis performed. How the microarray analysis was defined as a complete analysis of miRNA and citations would enhance the manuscript.

\section{Authors' response}

The 'complete miRNome' refers to the microarrays ( $\mu R N A$ microarrays) used for these experiments which contain probes against every known miRNA (the miRNome) as defined by the reference depository for miRNAs (miRBase- http://www.mirbase.org) (Griffiths-Jones et al (2006), Nucleic Acids Research, 34, D140-144). At the time when these experiments were started (June 2009), the miRBase version was 13.0 which included 655 human sequences. The authors readily accept that the miRNA database has grown since this time and that the current version of the miRBase miRNome is version 16 and contains 1048 human sequences. This assertion has been modified in the text to read 'complete miRNome (miRBase version 13.0)' in the text in order to avoid confusion.

2. The "leave-one-out cross-validation support vector machine algorithm" (mentioned on page 7) is not defined or described in the methods section. The support vector machine algorithm is also mentioned in the abstract but the manuscript would be improved by describing and referencing this technique.

\section{Authors' response}

The support vector machine (SVM) algorithm is a supervised learning method commonly used for classification in microarray experiments (along with k-nearest neighbor algorithm) and is based on non-probabilistic binary linear classification (Cortes E Vapnik (1995) Machine learning, 20). We believe that as the parameters used for its implementation within the Genespring package as described in the materials and methods section are already given, that this would be sufficient information for others to carry out the same analysis.

3 . In the results the authors state that 8 miRNA were chosen to be measured by qRT-PCR to validate the microarray data. They state, "These data were consistent with the microarray results". In the discussion the authors indicate that "miR-32 and miR-181a were identified as being up-regulated by microarray analysis" by qRT-PCR failed to show any significant differences in expression levels. Were there other miRNA studied by qRT-PCR? Why weren't miR-32 and miR181a included in Figure 2?

\section{Authors' response}

The eight miRNAs that were tested by qRT-PCR shown in Figure 2 were chosen on the basis that they were differentially expressed in our microarray analysis and had previously been shown to be dysregulated in MM or other hematological malignancies. As all of these miRNAs were also significantly differentially expressed when measured by qRT-PCR they were described as being 'consistent with the microarray data'. The only other miRNAs that we measured (miR-32 and miR-181a) by qRTPCR which were also chosen on the basis shown to be dysregulated in previous studies but we did not find them to be significantly different by qRT-PCR which is why the data was not included in Figure 2.

4. In the discussion the authors state that the investigators of reference 17 "only examined $10 \mathrm{MM}$ and 4 controls". In the abstract of this manuscript, Pichiorri et al. indicate that 16 samples from patients with MM 
were studied along with 6 with MGUS and 6 normal donors. Also, in this same spot of the discussion, the authors indicate that the investigators of reference 16 only studied 2 controls but the 52 patient samples analyzed was not mentioned. Moreover, the purpose of that study was to risk stratification.

\section{Authors' response}

These comments in the discussion were made in the context of the identification of aberrantly expressed miRNA associated with MM diagnosis. The Pichiorri study states in the results section (pg 12886) that their MM-associated miRNA signature was derived from the array data of $41 \mathrm{MM}$ cell lines, $10 \mathrm{MM}$ patients and 4 controls. Whereas for the Zhou et al study (pg 7904) the $M M$ miRNA signature was derived from a comparison of array data from $52 \mathrm{MM}$ cases with samples from 2 healthy donors. Whilst it is true that the Zhou et al study mainly focused on the identification of risk groups within the 52 MM cases, a significant part of the results section of this paper refers to the identity of miRNAs that are differentially expressed between controls and MM cases. The point that we were making in the discussion is that insufficient numbers of controls were used in both of these previous studies, and that our study was therefore an improvement on these studies, in the context of the identification of aberrantly expressed miRNAs in MM tumor cells.

\section{Acknowledgements and Funding}

This work was funded by grants from Leukaemia and Lymphoma Research (JC, EB, X-HC, DT, JB and JSW) and the Julian Starmer-Smith Memorial Fund (CHL). The authors acknowledge financial support from the Department of Health via the National Institute for Health Research (NIHR) comprehensive Biomedical Research Centre award to Oxford Radcliffe NHS Trust.

The authors wish to thank Maite Cabes, Graham Collins, Narendra Kaushik, Andy Campbell and Pamela Roberts (John Radcliffe Hospital) for their help in collecting patient material and collating clinical data. We are indebted to Fiona Ross and her colleagues at the LLR Myeloma Cytogenetic Database, Wessex Regional Genetic Laboratory, Salisbury, UK for their help in implementing and interpreting the microFISH technique as well as their input in the writing this manuscript.

\section{Additional material}

Additional file 1: Additional tables (Tables S1-S7) and figure (Figures S1-S4). Table S1. Clinical details of MM and MGUS patients. Table S2. Table of microRNAs aberrantly expressed in DLBCL, SZS and MM, highlighting those that are common. Table S3. MicroRNAs differentially expressed $(P<0.05)$ between MGUS $(n=5)$ and controls ( $n$ $=9$ ). Table S4. MicroRNAs differentially expressed $(P<0.05)$ between MM $(n=32)$ and MGUS $(n=5)$. Table S5. MicroRNAs differentially expressed $(P<0.05)$ between $\lg A(n=8)$ and $\lg G(n=13)$ isotype MM cases. Table S6. MicroRNAs differentially expressed $(P<0.05)$ between LC-only myeloma $(n=8)$ and non-LC-only myeloma MM cases $(n=21)$. Table S7. MicroRNAs associated with event-free survival (EFS) in MM cases. Figure S1. Heat map depicting cluster analysis of MM and control samples on the basis of expression values of $129 \mathrm{MM}$-associated microRNAs. Figure S2. Heat map depicting cluster analysis of MGUS and control samples on the basis of expression values of 39 MGUS-associated microRNAs. Figure S3. Venn-diagram depicting relationship between microRNAs differentially expressed in MGUS, MM and controls. Figure S4. Heat map depicting cluster analysis of $\lg G$ and $\lg A$ isotype MM cases on the basis of expression values of 21 isotype-associated microRNAs (Table S5).

\section{List of abbreviations}

ANOVA: analysis of variance; BCL2 - B-cell CLL/lymphoma 2; CCND1 - cyclin D1; DGCR8 - DiGeorge syndrome critical region gene 8; EFS: event-free survival; FGFR3 - fibroblast growth factor receptor 3; FISH: fluorescent in situ hybridization; HGMA1 - Homogentisate 1,2-dioxygenase; IgH:

immunoglobulin (heavy chain); LMO2 - LIM domain only 2 (rhombotin-like 1); MCL1 - myeloid cell leukemia sequence 1 (BCL2-related); MGUS: monoclonal gammopathy of undetermined significance; MIAME: Minimum Information About a Microarray Experiment; MM: multiple myeloma; PC: plasma cell; qRT-PCR: quantitative reverse transcriptase polymerase chain reaction; RB1 - retinoblastoma 1; SVM: support vector machine; SzS: Sezary syndrome;

\section{Author details}

${ }^{1}$ Nuffield Department of Clinical Laboratory Sciences, University of Oxford, John Radcliffe Hospital, Oxford, UK. ${ }^{2}$ The Center for the Study of Haematological Malignancies, Nicosia, Cyprus. ${ }^{3}$ Dubrava University hospital and Zagreb School of Medicine, University of Zagreb, Croatia. ${ }^{4}$ Computational Biology Research Group, Weatherall Institute of Molecular Medicine, University of Oxford, Oxford, UK. ${ }^{5}$ Department of Haematology, John Radcliffe Hospital, Oxford, UK. ${ }^{6}$ Sir William Dunn School of Pathology, University of Oxford, Oxford, UK.

\section{Authors' contributions}

Conceived and designed the experiments: JC CHL CSRH TL JB JSW FP. Performed the experiments: JC EB X-HC DT CHL. Analyzed the data: ST X-HC $\mathrm{CHL}$. Contributed reagents/materials/analysis tools: RK DH NJS. Wrote the paper: $\mathrm{CHL} J \mathrm{C}$. All authors read and approved the final manuscript.

\section{Competing interests}

The authors declare that they have no competing interests.

Received: 20 January 2011 Accepted: 18 May 2011

Published: 18 May 2011

\section{References}

1. Ries L, Eisner M, Kosary C: SEER Cancer Statistics Review, 1975-2001 Bethesda: National Cancer Institute; 2004.

2. Mateos MV, Richardson PG, Schlag R, Khuageva NK, Dimopoulos MA, Shpilberg O, Kropff M, Spicka I, Petrucci MT, Palumbo A, et al: Bortezomib plus melphalan and prednisone compared with melphalan and prednisone in previously untreated multiple myeloma: updated followup and impact of subsequent therapy in the phase III VISTA trial. J Clin Oncol 2010, 28:2259-2266.

3. Calin GA, Ferracin M, Cimmino A, Di Leva G, Shimizu M, Wojcik SE, lorio MV Visone R, Sever NI, Fabbri M, et al: A MicroRNA signature associated with prognosis and progression in chronic lymphocytic leukemia. N Engl J Med 2005, 353:1793-1801.

4. Iorio MV, Ferracin M, Liu CG, Veronese A, Spizzo R, Sabbioni S, Magri E, Pedriali M, Fabbri M, Campiglio M, et al: MicroRNA gene expression deregulation in human breast cancer. Cancer Res 2005, 65:7065-7070.

5. Lawrie $\mathrm{CH}$, Soneji S, Marafioti T, Cooper CD, Palazzo S, Paterson JC, Cattan H, Enver T, Mager R, Boultwood J, et al: MicroRNA expression distinguishes between germinal center $B$ cell-like and activated $B$ cell- 
like subtypes of diffuse large B cell lymphoma. Int J Cancer 2007, 121:1156-1161.

6. Lawrie CH, Gal S, Dunlop HM, Pushkaran B, Liggins AP, Pulford K, Banham AH, Pezzella F, Boultwood J, Wainscoat JS, et al: Detection of elevated levels of tumour-associated microRNAs in serum of patients with diffuse large B-cell lymphoma. Br J Haematol 2008, 141:672-675.

7. Lawrie CH, Chi J, Taylor S, Tramonti D, Ballabio E, Palazzo S, Saunders NJ, Pezzella F, Boultwood J, Wainscoat JS, Hatton CS: Expression of microRNAs in diffuse large B cell lymphoma is associated with immunophenotype, survival and transformation from follicular lymphoma. I Cell Mol Med 2009, 13:1248-1260.

8. Lu J, Getz G, Miska EA, Alvarez-Saavedra E, Lamb J, Peck D, SweetCordero A, Ebert BL, Mak RH, Ferrando AA, et al: MicroRNA expression profiles classify human cancers. Nature 2005, 435:834-838.

9. Lawrie $\mathrm{CH}$ : microRNA expression in lymphoid malignancies: new hope for diagnosis and therapy? J Cell Mol Med 2008, 12:1432-1444

10. Ballabio E, Mitchell T, van Kester MS, Taylor S, Dunlop HM, Chi J, Tosi I, Vermeer $\mathrm{MH}$, Tramonti D, Saunders NJ, et al: MicroRNA expression in Sezary syndrome: identification, function, and diagnostic potential. Blood 2010, 116:1105-1113

11. Zhou Y, Chen L, Barlogie B, Stephens O, Wu X, Williams DR, Cartron MA, van Rhee F, Nair B, Waheed S, et al: High-risk myeloma is associated with global elevation of miRNAs and overexpression of EIF2C2/AGO2. Proc Natl Acad Sci USA 107:7904-7909.

12. Pichiorri F, Suh SS, Ladetto M, Kuehl M, Palumbo T, Drandi D, Taccioli C, Zanesi $\mathrm{N}$, Alder $\mathrm{H}$, Hagan JP, et al: MicroRNAs regulate critical genes associated with multiple myeloma pathogenesis. Proc Natl Acad Sci USA 2008, 105:12885-12890

13. Lee $Y$, Jeon $K$, Lee JT, Kim S, Kim VN: MicroRNA maturation: stepwise processing and subcellular localization. EMBO J 2002, 21:4663-4670.

14. Kyle RA, Therneau TM, Rajkumar SV, Larson DR, Plevak MF, Offord JR, Dispenzieri A, Katzmann JA, Melton L: Prevalence of monoclonal gammopathy of undetermined significance. N Engl J Med , 3 2006, 354:1362-1369.

15. Zhan F, Huang Y, Colla S, Stewart JP, Hanamura I, Gupta S, Epstein J, Yaccoby S, Sawyer J, Burington B, et al: The molecular classification of multiple myeloma. Blood 2006, 108:2020-2028.

16. Fonseca R, Bergsagel PL, Drach J, Shaughnessy J, Gutierrez N, Stewart AK, Morgan G, Van Ness B, Chesi M, Minvielle S, et al: International Myeloma Working Group molecular classification of multiple myeloma: spotlight review. Leukemia 2009, 23:2210-2221.

17. Ross FM, Ibrahim AH, Vilain-Holmes A, Winfield MO, Chiecchio L, Protheroe RK, Strike P, Gunasekera JL, Jones A, Harrison CJ, et al: Age has a profound effect on the incidence and significance of chromosome abnormalities in myeloma. Leukemia 2005, 19:1634-1642.

18. Kuehl WM, Bergsagel PL: Early genetic events provide the basis for a clinical classification of multiple myeloma. Hematology (Am Soc Hematol Educ Program) 2005, 346-352.

19. Gutierrez NC, Sarasquete ME, Misiewicz-Krzeminska I, Delgado M, De Las Rivas J, Ticona FV, Ferminan E, Martin-Jimenez P, Chillon C, Risueno A, et al: Deregulation of microRNA expression in the different genetic subtypes of multiple myeloma and correlation with gene expression profiling. Leukemia 2010, 24:629-637.

20. Lionetti M, Biasiolo M, Agnelli L, Todoerti K, Mosca L, Fabris S, Sales G, Deliliers GL, Bicciato S, Lombardi L, et al: Identification of microRNA expression patterns and definition of a microRNA/mRNA regulatory network in distinct molecular groups of multiple myeloma. Blood 2009, 114:e20-26.

21. Greipp PR, San Miguel J, Durie BG, Crowley JJ, Barlogie B, Blade J, Boccadoro M, Child JA, Avet-Loiseau H, Kyle RA, et al: International staging system for multiple myeloma. J Clin Oncol 2005, 23:3412-3420.

22. Sirohi B, Powles R, Kulkarni S, Rudin C, Saso R, Lal R, Singhal S, Mehta J, Horton C, Treleaven J: Comparison of new patients with Bence-Jones, IgG and IgA myeloma receiving sequential therapy: the need to regard these immunologic subtypes as separate disease entities with specific prognostic criteria. Bone Marrow Transplant 2001, 28:29-37.

23. Kyle RA, Gertz MA, Witzig TE, Lust JA, Lacy MQ, Dispenzieri A, Fonseca $R$, Rajkumar SV, Offord JR, Larson DR, et al: Review of 1027 patients with newly diagnosed multiple myeloma. Mayo Clin Proc 2003, 78:21-33.

24. Shustik C, Bergsagel DE, Pruzanski W: Kappa and lambda light chain disease: survival rates and clinical manifestations. Blood 1976, 48:41-51.
25. Huang Q, Gumireddy K, Schrier M, le Sage C, Nagel R, Nair S, Egan DA, Li A, Huang G, Klein-Szanto AJ, et al: The microRNAs miR-373 and miR-520c promote tumour invasion and metastasis. Nat Cell Biol 2008, 10:202-210.

26. Lawrie CH, Saunders NJ, Soneji S, Palazzo S, Dunlop HM, Cooper CD, Brown PJ, Troussard X, Mossafa H, Enver T, et al: MicroRNA expression in lymphocyte development and malignancy. Leukemia 2008, 22:1440-1446.

27. Zhang J, Jima DD, Jacobs C, Fischer R, Gottwein E, Huang G, Lugar PL, Lagoo AS, Rizzieri DA, Friedman DR, et al: Patterns of microRNA expression characterize stages of human B cell differentiation. Blood 2009, 113:4586-4594.

28. Merkel O, Hamacher F, Laimer D, Sifft E, Trajanoski Z, Scheideler M, Egger G, Hassler MR, Thallinger C, Schmatz A, et al: Identification of differential and functionally active miRNAs in both anaplastic lymphoma kinase (ALK)+ and ALK- anaplastic large-cell lymphoma. Proc Natl Acad Sci USA 2010, 107:16228-16233.

29. Lawrie CH, Cooper CD, Ballabio E, Chi J, Tramonti D, Hatton CS: Aberrant expression of microRNA biosynthetic pathway components is a common feature of haematological malignancy. Br J Haematol 2009, 145:545-548.

30. Wong QW, Lung RW, Law PT, Lai PB, Chan KY, To KF, Wong N: MicroRNA223 is commonly repressed in hepatocellular carcinoma and potentiates expression of Stathmin1. Gastroenterology 2008, 135:257-269.

31. Fazi F, Racanicchi S, Zardo G, Starnes LM, Mancini M, Travaglini L, Diverio D, Ammatuna E, Cimino G, Lo-Coco F, et al: Epigenetic silencing of the myelopoiesis regulator microRNA-223 by the AML1/ETO oncoprotein. Cancer Cell 2007, 12:457-466.

32. Stamatopoulos B, Meuleman N, Haibe-Kains B, Saussoy P, Van Den Neste E, Michaux L, Heimann P, Martiat P, Bron D, Lagneaux L: microRNA-29c and microRNA-223 down-regulation has in vivo significance in chronic lymphocytic leukemia and improves disease risk stratification. Blood 2009, 113:5237-5245.

33. Lawrie CH, Ballabio E, Dyar OJ, Jones M, Ventura R, Chi J, Tramonti D, Gooding S, Boultwood J, Wainscoat JS, et al: MicroRNA expression in chronic lymphocytic leukaemia. Br J Haematol 2009, 147:398-402.

34. Felli N, Pedini F, Romania P, Biffoni M, Morsilli O, Castelli G, Santoro S, Chicarella S, Sorrentino A, Peschle C, Marziali G: MicroRNA 223-dependent expression of LMO2 regulates normal erythropoiesis. Haematologica 2009, 94:479-486.

35. Natkunam Y, Zhao S, Mason DY, Chen J, Taidi B, Jones M, Hammer AS, Hamilton Dutoit S, Lossos IS, Levy R: The oncoprotein LMO2 is expressed in normal germinal-center B cells and in human B-cell lymphomas. Blood 2007, 109:1636-1642.

36. Akao Y, Nakagawa Y, Kitade Y, Kinoshita T, Naoe T: Downregulation of microRNAs-143 and -145 in B-cell malignancies. Cancer Sci 2007, 98:1914-1920.

37. Landgren O, Kyle RA, Pfeiffer RM, Katzmann JA, Caporaso NE, Hayes RB, Dispenzieri A, Kumar S, Clark RJ, Baris D, et al: Monoclonal gammopathy of undetermined significance (MGUS) consistently precedes multiple myeloma: a prospective study. Blood 2009, 113:5412-5417.

38. Chan JA, Krichevsky AM, Kosik KS: MicroRNA-21 is an antiapoptotic factor in human glioblastoma cells. Cancer Res 2005, 65:6029-6033.

39. Si ML, Zhu S, Wu H, Lu Z, Wu F, Mo YY: miR-21-mediated tumor growth. Oncogene 2006, 26:2799-2803.

40. Fonseca R, Oken MM, Harrington D, Bailey RJ, Van Wier SA, Henderson KJ, Kay NE, Van Ness B, Greipp PR, Dewald GW: Deletions of chromosome 13 in multiple myeloma identified by interphase FISH usually denote large deletions of the q arm or monosomy. Leukemia 2001, 15:981-986.

41. He L, Thomson JM, Hemann MT, Hernando-Monge E, Mu D, Goodson S, Powers S, Cordon-Cardo C, Lowe SW, Hannon GJ, Hammond SM: A microRNA polycistron as a potential human oncogene. Nature 2005, 435:828-833.

42. Zojer N, Konigsberg R, Ackermann J, Fritz E, Dallinger S, Kromer E, Kaufmann H, Riedl L, Gisslinger H, Schreiber S, et al: Deletion of 13q14 remains an independent adverse prognostic variable in multiple myeloma despite its frequent detection by interphase fluorescence in situ hybridization. Blood 2000, 95:1925-1930.

43. Lawrie CH: MicroRNAs and haematology: small molecules, big function. Br J Haematol 2007, 137:503-512.

44. Cloonan N, Brown MK, Steptoe AL, Wani S, Chan WL, Forrest AR, Kolle G, Gabrielli B, Grimmond SM: The miR-17-5p microRNA is a key regulator of the G1/S phase cell cycle transition. Genome Biol 2008, 9:R127. 
45. Aguda BD, Kim Y, Piper-Hunter MG, Friedman A, Marsh CB: MicroRNA regulation of a cancer network: consequences of the feedback loops involving miR-17-92, E2F, and Myc. Proc Natl Acad Sci USA 2008, 105:19678-19683.

46. Hossain A, Kuo MT, Saunders GF: Mir-17-5p regulates breast cancer cell proliferation by inhibiting translation of AIB1 mRNA. Mol Cell Biol 2006, 26:8191-8201.

47. Xu J, Liao X, Wong C: Downregulations of B-cell lymphoma 2 and myeloid cell leukemia sequence 1 by microRNA 153 induce apoptosis in a glioblastoma cell line DBTRG-05MG. Int J Cancer 2010, 126:1029-1035.

48. Wuilleme-Toumi S, Robillard N, Gomez P, Moreau P, Le Gouill S, AvetLoiseau H, Harousseau JL, Amiot M, Bataille R: Mcl-1 is overexpressed in multiple myeloma and associated with relapse and shorter survival. Leukemia 2005, 19:1248-1252.

49. Hiroki E, Akahira J, Suzuki F, Nagase S, Ito K, Suzuki T, Sasano H, Yaegashi N: Changes in microRNA expression levels correlate with clinicopathological features and prognoses in endometrial serous adenocarcinomas. Cancer Sci 2010, 101:241-249.

50. Wei JJ, Wu X, Peng Y, Shi G, Olca B, Yang X, Daniels G, Osman I, Ouyang J,

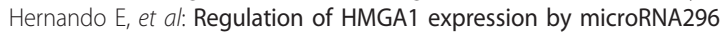
affects prostate cancer growth and invasion. Clin Cancer Res 2010.

51. Durie BG, Kyle RA, Belch A, Bensinger W, Blade J, Boccadoro M, Child JA, Comenzo R, Djulbegovic B, Fantl D, et al: Myeloma management guidelines: a consensus report from the Scientific Advisors of the International Myeloma Foundation. Hematol J 2003, 4:379-398.

52. Wuilleme S, Robillard N, Lode L, Magrangeas F, Beris H, Harousseau JL, Proffitt J, Minvielle S, Avet-Loiseau H: Ploidy, as detected by fluorescence in situ hybridization, defines different subgroups in multiple myeloma. Leukemia 2005, 19:275-278.

53. Smyth GK, Speed T: Normalization of cDNA microarray data. Methods 2003, 31:265-273.

doi:10.1186/1745-6150-6-23

Cite this article as: Chi et al:: MicroRNA expression in multiple myeloma is associated with genetic subtype, isotype and survival. Biology Direct $20116: 23$.

\section{Submit your next manuscript to BioMed Central and take full advantage of:}

- Convenient online submission

- Thorough peer review

- No space constraints or color figure charges

- Immediate publication on acceptance

- Inclusion in PubMed, CAS, Scopus and Google Scholar

- Research which is freely available for redistribution

Submit your manuscript at www.biomedcentral.com/submit 